\title{
Research and Practice of Mixed Teaching Methods Based on "Ketang Pai" Classroom Management Platform
}

\author{
Jie SU* \\ Department of Automation \\ North China Electric Power University \\ Baoding, China
}

\author{
Xin ZENG \\ Department of Automation \\ North China Electric Power University \\ Baoding, China
}

\begin{abstract}
Effective curriculum teaching is the key to talent training, which requires the reform of teaching methods to adapt to the current learning situation of the students. Mixed teaching methods is increasingly applied to teaching. The aim of this study was to implement mixed teaching methods using "Ketang pai" classroom management platform. The steps of implementing mixed teaching with the help of "Ketang pai" were discussed which were attempted in the course of Detection Theory and Application. It was also discussed that the advantages and disadvantages of the mixed teaching method in the teaching of this course. Although the workload of teachers has increased considerably in the implementation of mixed teaching methods, the results show that it not only improves the learning efficiency, but also stimulates the students' learning initiative, and has been recognized by the students.
\end{abstract}

Keywords—mixed teaching; flipped classroom; practice; course; Ketang pai

\section{INTRODUCTION}

Mixed teaching is a new teaching mode which is highly integrated with educational information technology and traditional classroom teaching. BonK and Graham define "mixed teaching" as a new form of teaching that combines face-to-face teaching with a variety of technical media [1]. Through the combination of "online" and "offline" teaching forms, we can transform our conventional teaching methods and change the current situation that we use too much oral teaching in class, which leads to students' little interest and enthusiasm in learning, insufficient participation, excessive differences in learning outcomes between different students, and so on. Diversified teaching methods may guide students from simple to in-depth learning. The influence of network and information is that the traditional education mode is changed to the digital teaching mode.

Specifically, the mixed teaching method is that teachers accomplish the teaching objectives and various teaching tasks using modern information technology in the teaching process. With the aid of the teaching platform, teachers can complete teaching design, development and production of teaching content, curriculum construction and curriculum operation. It mainly includes three aspects:(1) Before class, teachers put the basic theory on the online teaching platform for students to learn independently in a hierarchical interactive way, such as microvideo, pictures, audio, animation, and online testing. After learning the contents assigned by the teacher, the students should complete the corresponding test questions. (2) According to the feedback such as error rate and pageviews, the teacher can discover the difficulties the students encounter when preparing so that knowledge points are covered and explained in class and the teacher can interact with students. (3) After class, the teacher releases tests to guide students to review what they learn, supervising the completion of tasks in real time through the network platform. By tracking students' learning behavior, the teacher can provide personalized guidance and assistance to students. The mixed teaching framework is shown in Fig. 1.

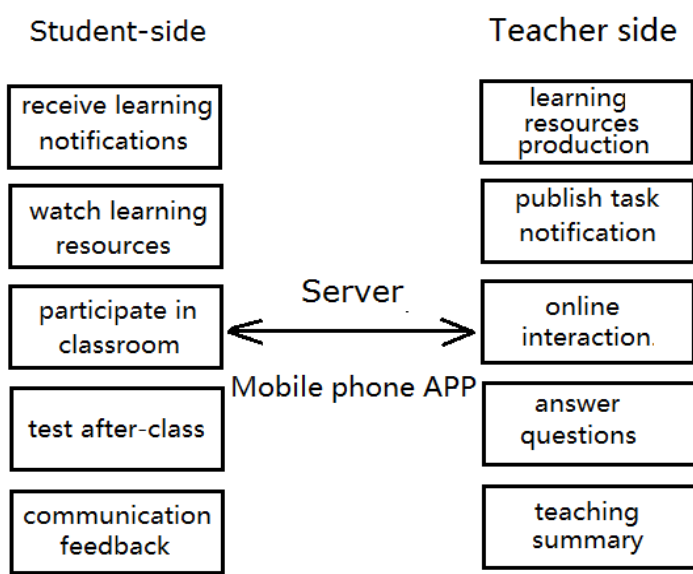

Fig. 1. Mixed teaching framework

From the above introduction, it is obvious that in order to introduce mixed teaching into the classroom, it is indispensible to use online resources, offline activities and process evaluation. Current education has entered the era of "Internet +". With the continuous emergence of information technologies such as cloud computing, big data, artificial intelligence, and so on, everyone can learn all kinds of knowledge from the Internet. This also provides technical support for the development of mixed teaching. 


\section{ANALYSIS OF THE BASIC CONDITIONS FOR THE IMPLEMENTATION OF MIXED TEACHING}

The implementation of mixed teaching should have certain basic conditions, including classroom management platform as well as curriculum and classes to apply the platform. Here, "Ketang pai" is chosen as the network teaching platform, and the detection theory and application course of graduate students as the course of mixed teaching. The basic information and reasons for the choice of the classroom management platform and course are described below.

\section{A. An Auxiliary Tool for Realizing Mixed Teaching "Ketang pai”}

"Ketang pai" is an online classroom management platform, which not only facilitates the interaction between teachers and students, but also helps to flip the classroom. It can provide teachers with convenient class management, homework online correction, performance summary analysis and courseware sharing. WeChat public platform is used by "Ketang pai" as an important interactive medium between teachers and students. It has the characteristic of powerful function, simple and easy to use, efficiency and convenience. That's the reason why "Ketang pai" is chosen as the classroom management platform to realize mixed teaching.

When using "Ketang pai", teachers should first pay attention to WeChat official account of "Ketang pai" and follow the prompts to create new classes and specific courses. When the class is created successfully, the teacher can ask the students to join the class by inputting the invitation code.

"Ketang pai” login interface used by teacher is shown in Fig. 2. Either computer version or mobileWeChat version can be selected to use. The function in computer version of "Ketang pai" is functional. Teachers can upload courseware, videos and put the results of the test on the screen to interact in the classroom. The mobile version of "Ketang pai" is userfriendly. Teachers can complete tests and interactions using mobile phones when the computers in the classroom are not connected to the Internet. The use of "Ketang pai" can also complete the functions of online homework correction, classroom roll call, communication between teachers and students and answering questions. The realization of mixed teaching involved in this paper is accomplished with the help of "Ketang pai".

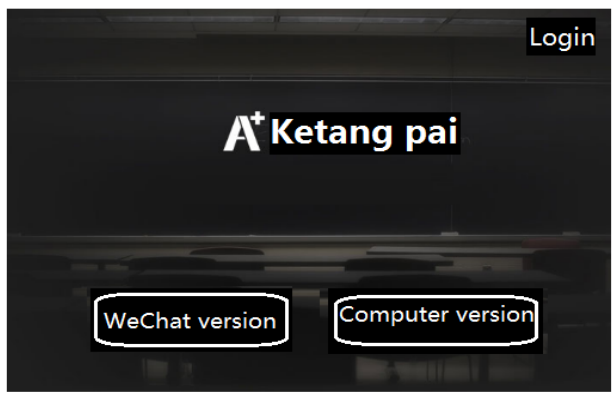

Fig. 2. “Ketang pai” login interface

\section{B. Analysis on the Present Situation of Teaching of Detection Theory and Application Course}

"Detection Theory and Application" is a degree course for students majoring in control engineering in NCEPU, 32 hours. This course mainly involves the advanced detection theories and the application of them. The students in class have finished undergraduate education so they have great capacity for learning. However, there are also some problems in the teaching process, mainly because the current class is still using traditional teaching model, which means teachers use the combination of theoretical explanation, blackboard writing and multimedia. Students are still in a passive state in the process of accepting knowledge, which is not conducive to the cultivation of students' independent thinking ability. Due to the strong theoretical nature of the curriculum, the students' learning autonomy is still relatively weak, and some students lose interest in learning, leading to a phenomenon of using mobile phones in class.

In the past, we also tried to change the existing teaching situation, such as strengthening the interaction with students, communicating after class, but the participation of students is not active. So we decided to change the teaching method and use the mixed teaching method in the teaching of this course.

\section{Realization Method of Mixed Teaching Mode USING “KETANG PAI”}

The following methods are adopted to realize mixed teaching.

\section{A. The Steps of Realizing the Flipped Classroom with the Help of "Ketang pai"}

The mixed teaching mode based on the flipped classroom is to apply modern information and network technology to the curriculum. The general teaching mode of the reversal of classroom is to watch the relevant teaching videos before class, carry out the pre-class exercises pertinently, and complete the internalization of knowledge through a small amount of rapid evaluation, group discussion, learning report and so on for the learners. Finally, the relevant summary and feedback are carried out. [3]

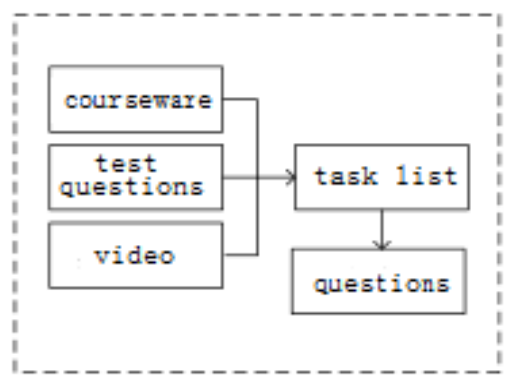

Fig. 3. Block diagram of pre-class preparation

Considering the situation of the teaching object, some of the contents of the course are selected to realize the flipped classroom at present, such as the basic knowledge of detection theory (artificial neural network, genetic algorithm, etc.). First of all, the classroom explanation content is divided into 
several small knowledge points, recorded by videos, and then uploaded to the class data area using "Ketang pai" (computer version). Its announcement function is used to inform students of the content to learn. After the students have finished their study, they can independently complete the test questions in the test area. Pre-class preparation part is shown in Fig. 3.

It is convenient for teachers to understand the students' mastery in time. For the problems encountered in learning, students can communicate with teachers through the private letter function in "Ketang pai".

The classroom teaching process is chiefly in the form of face-to-face teaching, and the teacher focuses on explaining common problems existing in the preview task for the students according to preview data. The block diagram of classroom teaching is shown in Fig. 4. In this part, teachers can also introduce some cutting-edge topics and disputes for students in order to promote their scientific research ability.

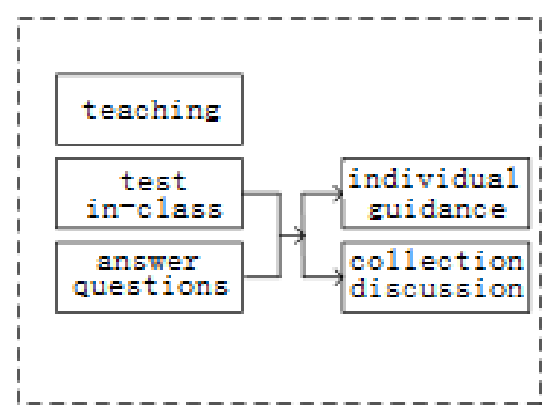

Fig. 4. Block diagram of classroom teaching

Block diagram of review after class is shown in Fig. 5. Students can review the teaching courseware and finish test questions issued by the teacher through "Ketang pai" to consolidate the relevant knowledge. Questions and doubts can be posted on the discussion forum, and teachers can answer them online.

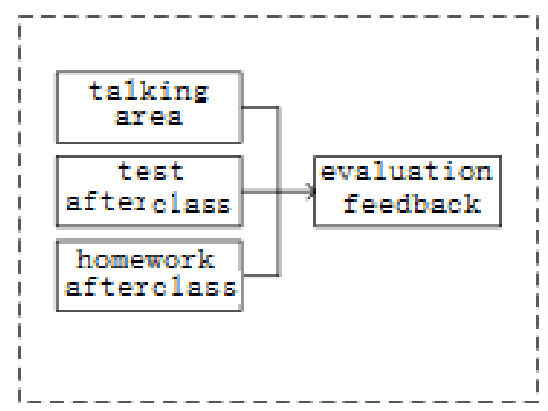

Fig. 5. Block diagram of review after class

According to the statistical data in the above three links, teachers can analyze and improve the learning effect.

By the reversal of classroom, the students are changed from passive listening to active listening, from listening blindly to listening with problems.
B. The Way to Realize the Interaction between Teachers and Students in Class by Using "Ketang pai"

- The key to improving the efficiency of classroom teaching is to mobilize students' interest in learning, which is an significant psychological factor of students' learning motivation and the source of students' desire for knowledge. Using the "Ketang pai" (mobile version), teachers can release test questions and interactive questions to students at any time and test students' mastery of knowledge points in a timely manner. Students are required to anser time-limited questions to check what they learned. Teachers further adjust the teaching progress according to the classroom feedback data to achieve more targeted and effective teaching. At the same time, according to the content of the class a reasonable topic is arranged for students so that they can discuss and speak, deepening their understanding of knowledge, while active participants can be rewarded.

- The bullet screen of "Ketang pai" can realize interactive teaching very well. By sending the bullet screen online, students can ask questions anonymously or put forward classroom suggestions, which can effectively improve the efficiency of classroom communication and enliven the classroom atmosphere. Interaction in the form of bullet screen in classroom teaching is a kind of discussion activity in which all students participate, which not only better meets the inner needs of students, makes the classroom interaction more stylish, but also effectively narrows the distance between teachers and students. Phenomenon may be avoided of the students unable to communicate with the teacher because of timidity or seat away and so on. [4]

\section{The Realization Method of Consolidating the Learning Achievement after Class Using "Ketang pai"}

The richness of learning resources, the scientific arrangement of teaching design, and the rationality of learning tasks and forms are all important conditions for the smooth progress of after-class review. Combined with the specific needs of after-class review, "Ketang pai" can be used to complete homework push, after-class testing, teaching resource sharing, doubt and difficulty feedback and so on. Homework is a major form of consolidating and reviewing knowledge. The content of homework can be transmitted to each student with the help of "Ketang pai", while the specific contents, requirements and learning resources needed can also be integrated into the courseware. The after-class test is a direct embodiment of the students' learning effect. In the afterclass test, several test methods can be used such as selection, question and answer or discussion. Objective questions can be automatically corrected by teachers. Subjective questions require students to upload their answers to the system in the form of photos, which can be reviewed by teachers. 


\section{Analysis After The Practice of Mixed Teaching METHOD}

Using the method introduced above, we have implemented the mixed teaching in the teaching of "Detection Theory and Application". Through the teaching process, we find that the use of this teaching method has both advantages and disadvantages, summarized as follows.

\section{A. Advantages}

The mixed teaching reform implemented by "Ketang pai" breaks the limitation of time and space and gives full play to the advantages of "online" plus "offline" teaching. The flipped classroom has further cultivated the students' learning ability, and the various interactions in the class have solved the problems such as the students' low interest in learning and the low degree of participation in the traditional classroom of "Detection Theory and Application". TABLE I shows the results of students' classroom evaluation of the course "Detection Theory and Application" before the reform.

TABLE I. STUDENTS' CLASSROOM GRADING BEFORE THE REFORM

\begin{tabular}{|c|c|c|c|}
\hline School year & 2014-2015 & 2015-2016 & 2016-2017 \\
\hline Classroom score & 87.2 & 86.7 & 87.5 \\
\hline
\end{tabular}

TABLE II shows the results of students' classroom evaluation of the course "Detection Theory and Application" after the reform. Mixed teaching began in the 2017-2018 school year. Through the data analysis of the classroom quality evaluation results, it can be seen that the students also agree with this teaching model.

TABLE II. STUDENTS' CLASSROOM GRADING AFTER THE REFORM

\begin{tabular}{|c|c|c|}
\hline School year & 2017-2019 & 2018-2019 \\
\hline Classroom score & 94.8 & 95.5 \\
\hline
\end{tabular}

\section{B. Disadvantages}

In the process of teaching, we also find several problems:

1) Increasing the Workload of Teaching Preparation.

Teachers should adopt "Ketang pai" in teaching according to the teaching effect which needs to make timely adjustments and changes to the courseware and should also prepare each section test question. All of this adds a lot of extra work.

\section{2) Reliability of Statistical Data.}

Class test questions online are unified released, whose time for answering can be controled by setting the time node of "Ketang pai". However, it is still unable to guarantee the independence and authenticity of the answer, so that the statistics of the reliability of the data is reduced.

\section{CONCLUSION}

This paper studies the mixed teaching method based on "Ketang pai" in the teaching of "Detection Theory and Application". The mixed teaching mode based on flipped classroom is to be applied. Flipped classroom consists of three stages of Pre-class preparation, classroom teaching, review after class. The design and activities of the three stages is discussed in this paper.

"Ketang pai" has played an important role in the realization of mixed teaching. With the help of the teaching platform of "Ketang pai", the classroom can be turned over and students are provided with more comprehensive learning materials. At the same time, it provides more reference data for teacher guidance.

"Internet + " is an important driving force for the change of the traditional education mode at present. The emergence of the mixed teaching model is to integrate the advantages of the traditional teaching model and web-based learning, and changes the situation in which teachers are keeping teaching and students are only listening. Through a variety of teaching means, teaching interaction, data feedback and other measures, it not only makes effort to the guidance of teachers in the classroom, but also greatly contributes to increaing the degree of participation of students in the classroom. At the same time, it can also keep abreast of the learning situation of students after class.

Through the mixed teaching work carried out in the past two years, I feel that this teaching model is rather effective to improve the teaching effect. However, teaching workload has increased a lot than the original for the implementation of mixed teaching. In addition, it is also felt that there is no unified model of mixed teaching, but there is a unified pursuit. In the future, the comparative study of various mixed teaching methods and the research on the teaching design of various specialties and courses will definitely become the development trend.

\section{REFERENCES}

[1] Xiaodong Zheng, “Application and Research of mixed Teaching Model based on Intelligent Teaching tools," Journal of Office Automation. Beijing , vol.296, pp. 13-15, April 2019.( In Chinese)

[2] Xueyin Yang,"Application of mixed Teaching in Engineering Materials and Machinery Manufacturing Foundation," Use and maintenance of Agricultural Machinery..Harbin, vol.124, pp.73-74, April 2019. (In Chinese)

[3] Min Deng, "Research on the Application of Rain classroom mixed Teaching Model in the context of Internet,” Journal of higher Education. Harbin, vol.167, pp.100-102, 2019. (In Chinese)

[4] Jing Peng, "Application of mixed Teaching Model based on flipped classroom in signal and system Analysis Teaching,” Northwest quality education, qinghai, pp.112-114, 2019. (In Chinese)

[5] Songgen Jin, "Reform of mixed Teaching Mode of Postgraduate Literature Retrieval course,” Journal of Mudanjiang Medical College.Mudanjiang. Mudanjiang, vol.40, pp.153-155, 2019. (In Chinese)

[6] Xuao Chen, Honglin Wang, "A probe into the mixed teaching model of task-driven, learning-oriented and process management," Journal of Ankang University. Shanxi, vol.31, pp. 123-128, August 2018 (In Chinese).

[7] Yuhong Li, “Application and comparative analysis of the mainstream classroom interactive tools from the perspective of higher vocational education,” China's educational technology and equipment. Beijing, vol.448, pp.34-36, November 2018(In Chinese)

[8] Liqin Zhao, Mingyan Dang, "Research on flipping classroom Teaching Mode of Chemical Engineering principle course based on Mobile Teaching platform,” Journal of Liaoning Teachers College. Shenyang, vol.19, pp. 13-15, September 2017 (In Chinese). 